Journal of Clinical Investigation

Vol. 41, No. 10, 1962

\title{
SITES OF INITIAL REMOVAL OF CHYLOMICRON TRIGLYCERIDE FATTY ACIDS FROM THE BLOOD*
}

\author{
By P. J. NESTEL, $\dagger$ R. J. HAVEL, $\ddagger$ AND A. BEZMAN § \\ (From the Cardiovascular Research Institute and the Department of Medicine, University of \\ California School of Medicine, San Francisco, Calif.)
}

(Submitted for publication March 26, 1962; accepted June 28, 1962)

After absorption from the small intestine, the long-chain fatty acids of dietary origin enter the blood primarily as glycerides in chylomicrons. The removal and subsequent distribution in tissue of triglyceride fatty acids (TGFA) in chylomicrons has generally been studied after intravenous administration of isotopically labeled lymph chylomicrons (1-7). Borgström and Jordan have shown that chylomicron triglycerides enter the liver without prior hydrolysis, and have proposed that under physiologic conditions the liver is the principal site of chylomicron removal (6). They have interpreted the time course of the deposition of chylomicron TGFA in adipose tissue to indicate that these fatty acids are derived from lipoproteins previously synthesized in the liver. On the other hand, a very considerable portion of radioactivity is found in adipose tissue soon after infusion of labeled chylomicrons, especially in rats fed carbohydrates (4), and chylomicron removal proceeds efficiently even in hepatectomized dogs (7).

To evaluate the relation of the liver to extrahepatic tissues with respect to chylomicron removal in the intact animal, we have measured the flux of radioactivity derived from chylomicron TGFA through the liver to determine the extent to which the radioactivity of triglycerides leaving the liver might account for the activity found in extrahepatic tissues, particularly adipose tissue.

We have also attempted to evaluate this problem by labeling the chylomicron TGFA with both $\mathrm{C}^{14}$ and $\mathrm{I}^{131}$. Since $\mathrm{I}^{131}$-labeled fatty acids are partially de-iodinated in the liver (8), it seemed

\footnotetext{
* Supported in part by U. S. Public Health Service grants $\mathrm{H}-6285$ and $\mathrm{H}-2554$.

$\dagger$ Fellow of the Life Insurance Medical Research Fund of Australia and New Zealand; permanent address, Department of Medicine, University of Melbourne, Australia.

$\ddagger$ Established Investigator, American Heart Association.

$\S$ Postdoctoral Research Fellow, U. S. Public Health Service.
}

possible that TGFA derived from chylomicrons and very low density lipoproteins of hepatic origin could be differentiated.

\section{METHODS}

A dog's thoracic duct was cannulated. On the following day the dog was given $300 \mu \mathrm{c}$ of sodium palmitate1-C ${ }^{14}$ (Research Specialties Co., Richmond, Calif.) and $1 \mathrm{mc}$ of sodium oleate- $\mathrm{I}^{181}$ (Abbott Laboratories, North Chicago, Ill.) with $10 \mathrm{~g}$ of milk fat. Chyle was collected for 8 hours and stored at $4^{\circ} \mathrm{C}$ for as long as 1 week. The chylomicrons were separated just before use by placing the chyle in a layer under $0.15 \mathrm{M}$ saline and centrifuging at $20,000 \mathrm{rpm}$ for 30 minutes in the 30 rotor of a Spinco Model L ultracentrifuge. They were collected with the aid of a tube slicer and then resuspended in saline.

Four male dogs, weighing 8 to $16 \mathrm{~kg}$, were the recipients. Two were fasted for 36 hours ("fasted"), and the other two were fed normally and then given an additional $10 \mathrm{~g}$ glucose intravenously for the 2 hours preceding the experiment ("fed"). They were anesthetized with Nembutal (pentobarbital sodium, Abbott), $30 \mathrm{mg}$ per $\mathrm{kg}$ intravenously, and their blood pressure and pulse rate were continuously monitored through a catheter in a femoral artery. A midline laparotomy was performed. Chylomicrons were infused intravenously at a constant rate of about $4 \mathrm{mg}$ per $\mathrm{kg}$ body weight per minute for 45 minutes. During the infusion, samples of blood were collected into chilled, heparinized tubes at 5, 15, 30, and 45 minutes. Specimens of liver and omental adipose tissue were obtained at the same times. Bleeding from liver biopsy sites was kept to a minimum by application of Gelfoam (Upjohn) soaked in thrombin solution. The tissues were weighed and homogenized at once, and the lipids were extracted in alcohol-acetone $1: 1$ by volume. At the end of each experiment, the liver was removed and weighed.

Plasma lipoproteins were separated into a creamy supernatant layer of chylomicrons and very low density lipoproteins ("top") and an infranatant layer containing the other lipoproteins ("bottom") by centrifuging plasma at a density of 1.006 for 16 hours at $115,000 \times G$ in the 40 rotor of a Spinco Model L ultracentrifuge at about $10^{\circ} \mathrm{C}$. The two fractions were separated with a tube slicer. The lipids were extracted from the top fractions in chloroform-methanol $2: 1$ by volume, which was sepa- 
rated into a two-phase system by the addition of $1 / 5$ volume $0.02 \mathrm{~N} \mathrm{HCl}$. The bottom fractions were extracted according to the method of Davis (9) and then further separated into triglycerides and free fatty acids (FFA) by the method of Borgström (10).

Portions of the lipid extracts of the liver and of the top fractions of plasma were separated into triglyceride and phospholipid fractions on silicic acid columns (11). Radioactivity and glyceride gycerol concentration were measured on the triglyceride fraction.

Since adipose tissue lipids consist almost entirely of triglycerides, radioactivity was measured on portions of the whole extracts without further separation.

Glyceride glycerol was measured by the method of Carlson (12) and FFA by the method of Dole (13). TGFA and FFA were calculated as palmitic acid. Radioactivity was assayed in a Packard Tricarb liquid scintillation counter with 0.3 per cent diphenyloxazole in toluene as scintillator-solvent. $\mathrm{C}^{14}$ and $\mathrm{I}^{131}$ were measured simultaneously at two separate pulse-height discriminator settings, one of which recorded only carbon counts. The $\mathrm{I}^{131}$, radioactivity was measured from the counts in the other channel after appropriate correction for contaminating $\mathrm{C}^{14}$.

\section{RESULTS}

Distribution of radioactivity in plasma and tissues. When chylomicrons were infused at a constant rate, the specific activity of the TGFA in the top (chylomicron + very low density lipoprotein) fraction of plasma remained constant, but the concentration of radioactivity and TGFA in this plasma fraction rose at a constant rate. Less than 2 per cent of the plasma radioactivity was in the TGFA of the bottom fraction at any time. Radioactivity in hepatic triglycerides and in adipose tissue lipids also increased at a virtually linear rate (Figure 1).

The fraction of the infused chylomicron TGFA radioactivity that was removed from the plasmathe difference between total infused radioactivity and total plasma radioactivity-remained fairly constant and was distributed in liver and adipose tissue in the percentages shown in Table $I$ and Figure 1. These values have been calculated with the assumption 1) that there is an even distribution of radioactivity throughout the liver, 2) that adipose tissue represents 5 per cent of body weight, and 3 ) that plasma volume represents 5 per cent of body weight. In three of the experiments, radioactivity in hepatic TGFA remained a reasonably constant proportion about one-third of the radioactivity that was being removed from plasma.

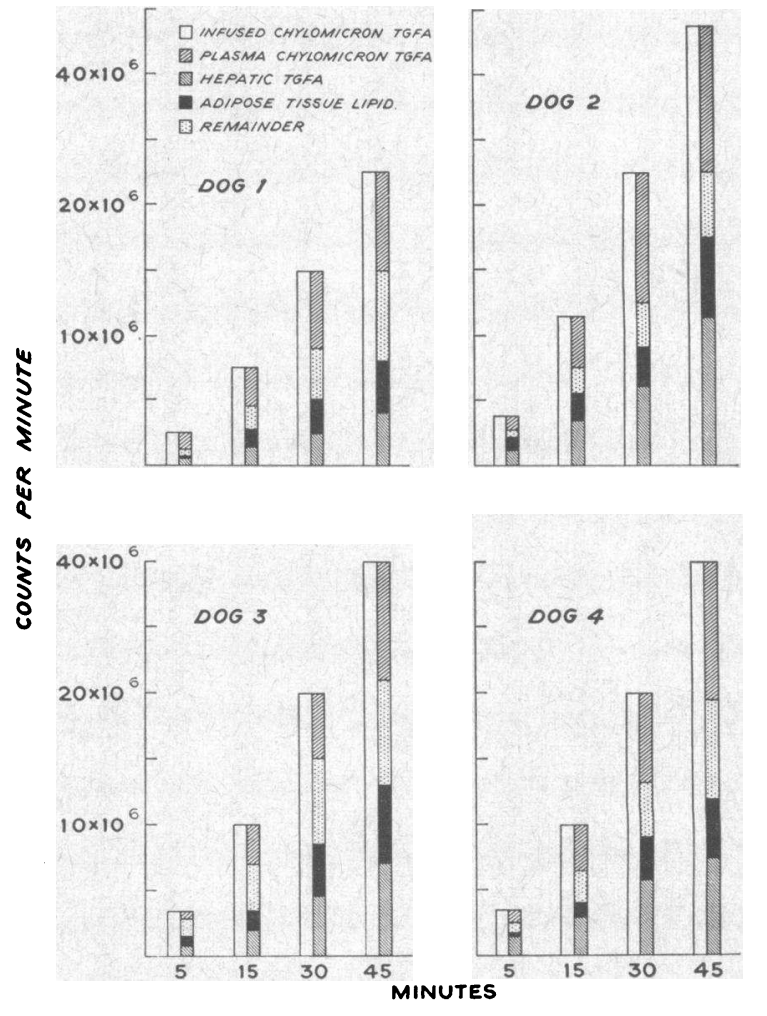

Fig. 1. $\mathrm{C}^{14}$ RAdioactivity IN TGFA OF ADMINISTERED CHYLOMICRONS, PLASMA CHYLOMICRONS, AND LIVER, AND IN ADIPOSE TISSUE LIPIDS DURING CONSTANT INFUSION OF CHYLOMICRONS LABELED WITH PALMITIC ACID-1-C ${ }^{14}$.

TABLE I

Per cent distribution of radioactivity in lipids of tissues during constant infusions of chylomicrons containing labeled TGFA*

\begin{tabular}{lllll}
\hline & \multicolumn{4}{c}{ Minutes of infusion } \\
\cline { 3 - 6 } Dog Tissue & 5 & 15 & 30 & $\mathbf{4 5}$ \\
\hline 1 (fed) & & & & \\
Hepatic TGFA & 28 & 35 & 27 & 22 \\
Adipose tissuet & 10 & 20 & 28 & 33 \\
Remainder & 62 & 45 & 45 & 45 \\
2 (fed) & & & & \\
Hepatic TGFA & 40 & 39 & 33 & 40 \\
Adipose tissue & 26 & 20 & 14 & 23 \\
Remainder & 34 & 41 & 53 & 37 \\
3 (fasted) & & & & \\
Hepatic TGFA & 36 & 32 & 31 & 31 \\
Adipose tissue & 30 & 25 & 29 & 34 \\
Remainder & 34 & 43 & 40 & 35 \\
(fasted) & & & & \\
Hepatic TGFA & 60 & 40 & 35 & 32 \\
Adipose tissue & 6 & 15 & 20 & 20 \\
Remainder & 34 & 45 & 45 & 48 \\
\hline
\end{tabular}

* TGFA = triglyceride fatty acids.

$\dagger$ Assumed to be 5 per cent of body weight. 
TABLE II

Hepatic TGFA concentrations during constant infusions of chylomicrons*

\begin{tabular}{ccccc}
\hline & \multicolumn{4}{c}{ Minutes of infusion } \\
\cline { 2 - 5 } Dog & 5 & 15 & 30 & 45 \\
\hline 1 (fed) & 4.8 & 4.5 & 4.5 & 4.7 \\
2 (fed) & 5.8 & 5.3 & 5.3 & 5.6 \\
3 (fasted) & 8.9 & 7.7 & 6.9 & 7.0 \\
4 (fasted) & 8.7 & 5.3 & 6.2 & 5.7 \\
\hline
\end{tabular}

* Concentrations in milligrams per gram of wet weight.

Since the concentration of TGFA in the liver did not vary greatly throughout the infusions (Table II), the linear increase of the specific activity of hepatic TGFA reflected the rise in their radioactivity. Radioactivity in the phospholipid fractions constituted about one-tenth of the total radioactivity in hepatic lipids.

In dogs 2 and 3 , a fairly constant fraction of radioactivity removed from plasma was taken up by adipose tissue; in $\operatorname{dogs} 1$ and 4 this fraction increased with time. This was not related to the nutritional state of the animals. In two of the dogs, radioactivtiy in perirenal and subcutaneous adipose tissue was approximately half that in omental adipose tissue at the end of the experiments.

At any one time the total radioactivity in plasma, liver, and adipose tissue rarely exceeded 75 per cent of infused radioactivtiy ; the rest had presumably been oxidized or deposited in other tissues, for example, muscle.

The specific activity of plasma FFA rose steadily with time. At the end of 45 minutes, it was almost half that of the infused chylomicrons (Figure 2). The concentration of plasma FFA rose by about one-half during the first 15-minute period and varied little thereafter. The concentration of

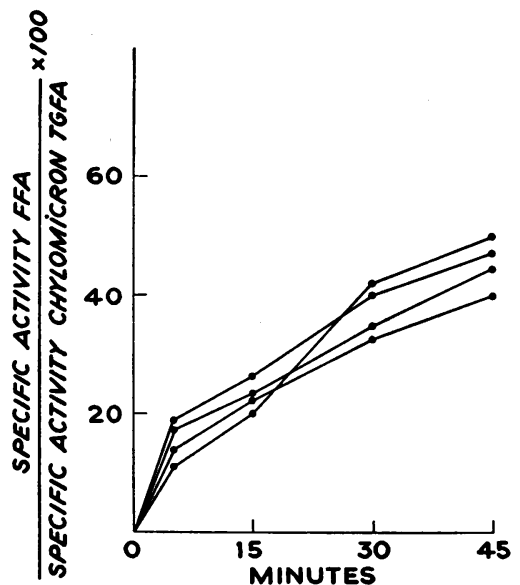

Fig. 2. Specific activity of plasma free fatty ACIDS DURING THE INTRAVENOUS INFUSION OF CHYLOMICRONS LABELED WITH PALMITIC ACID-1-C ${ }^{14}$.

plasma FFA in the fed dogs was about one-third that in the fasted dogs.

Turnover rate of hepatic TGFA. The calculation of the turnover rate of hepatic TGFA was based on the fact that the specific activity of TGFA of infused chylomicrons remained constant. These chylomicrons represented the major precursor of the radioactive TGFA in the liver. It was assumed that plasma FFA were a further precursor and that hepatic TGFA comprised a single pool for the purposes of the experiment. The appropriate calculations were derived from the equation given by Zilversmit (14),

$$
(\mathrm{SB})_{\mathrm{t}_{1}} /(\mathrm{SB})_{\mathrm{t}_{2}}=1-\mathrm{e}^{-\mathrm{K}_{2} \mathrm{t}_{1}} / 1-\mathrm{e}^{-\mathrm{K}_{2} \mathrm{t}_{2}} \text {, }
$$

where $\mathrm{SB}$ is the specific activity of the product $B$ at any time $t$, and $K_{2}$ is the fractional turnover rate of the product. From this equation, Zilversmit has constructed a series of curves that relate the product of fractional turnover rate and time

TABLE III

Turnover rates of hepatic TGFA

\begin{tabular}{|c|c|c|c|c|c|c|c|}
\hline \multirow[b]{3}{*}{ Dog } & \multicolumn{5}{|c|}{ Fractional turnover rate (per hour) } & \multirow{3}{*}{$\begin{array}{c}\text { Hepatic } \\
\text { TGFA } \\
\text { content }\end{array}$} & \multirow{3}{*}{$\begin{array}{c}\text { Turnover } \\
\text { rate }\end{array}$} \\
\hline & \multicolumn{4}{|c|}{ Minutes } & \multirow[b]{2}{*}{ Mean } & & \\
\hline & $0-5$ & $5-15$ & $15-30$ & $\overline{30-60}$ & & & \\
\hline $\begin{array}{l}1 \\
2 \\
3 \\
4\end{array}$ & $\begin{array}{l}1.02 \\
0.30 \\
0.55 \\
0.70^{*}\end{array}$ & $\begin{array}{l}1.14 \\
0.33 \\
0.68 \\
1.24\end{array}$ & $\begin{array}{l}0.90 \\
0.34 \\
0.72 \\
1.18\end{array}$ & $\begin{array}{l}0.95 \\
0.36 \\
0.62 \\
1.19\end{array}$ & $\begin{array}{l}1.00 \\
0.33 \\
0.64 \\
1.20\end{array}$ & $\begin{array}{c}m g \\
890 \\
1,290 \\
2,590 \\
1,890\end{array}$ & $\begin{array}{c}m g / h o u r \\
1,070 \\
1,290 \\
855 \\
1,210\end{array}$ \\
\hline
\end{tabular}

* Omitted from calculation of mean. 
$\mathrm{Kt}$ to the ratios of specific activities at two different times $(\mathrm{SB})_{\mathrm{t}_{1}} /(\mathrm{SB})_{\mathrm{t}_{2}}$. Fractional turnover rates were calculated from these curves for the various time intervals in each of the 4 experiments. Within each experiment the various fractional turnover rates were similar for the different time intervals. Since the concentration of TGFA in the liver remained at almost the same level, the turnover rate of hepatic TGFA varied only slightly throughout each experiment. Table III shows the fractional turnover rates and turnover rates of hepatic TGFA in the 4 dogs. The fractional rates were inversely related to the TGFA content of liver.

Since the increase in specific activity of hepatic TGFA was reasonably linear, mean specific activities could be calculated for each sampling period. The radioactivity leaving the liver over any given period was calculated from the product of the mean specific activity and the turnover rate of hepatic TGFA. It was then possible to determine the extent to which the radioactivity leaving the liver could account for the radioactivity in compartments other than liver and plasma. ${ }^{1}$ The

\footnotetext{
1 Hepatic TGFA in rats (15) and rabbits (11) do not consist of a homogeneous pool, so that in our experiments, chylomicron TGFA could have entered a small pool within the liver, which delivers TGFA back into the blood rapidly in relation to their rate of equilibration with the bulk of hepatic TGFA. This would cause us to underestimate the rate of extrahepatic transport of these TGFA. If this were so, radioactivity should have accumulated in hepatic TGFA at a progressively increasing rate, and the calculated turnover rate should have fallen progressively with time. In fact, the rate of increase of radioactivity was practically linear with time, and the turnover rates calculated at different times during the experiment varied little. It is also of interest that the turnover rates were similar in spite of widely varying hepatic content of TGFA (Table III), a similarity that would be unlikely if the turnover rate of TGFA derived from plasma chylomicrons were inde-
}

TABLE IV

Flux of TGFA radioactivity through the livers of 4 dogsper cent radioactivity found in extrahepatic tissues or oxidized

\begin{tabular}{ccccc}
\hline & \multicolumn{4}{c}{$\%$ Radioactivity } \\
\cline { 2 - 5 } Dog & 5 min & 15 min & 30 min & 45 min \\
\hline 1 & 2 & 7 & 10 & 16 \\
2 & 2 & 7 & 10 & 15 \\
3 & 1 & 3 & 5 & 8 \\
4 & 4 & 6 & 10 & 15 \\
\hline
\end{tabular}

calculations for the first 5 minutes of the experiment on $\operatorname{dog} 2$ are as follows. The mean specific activity of hepatic TGFA was $432 \mathrm{cpm}$ per $\mathrm{mg}$. Since the turnover rate was $100 \mathrm{mg}$ per $5 \mathrm{~min}$ utes, $43,200 \mathrm{cpm}$ of radioactivity was removed from the hepatic TGFA compartment during those 5 minutes. Of 3,730,000 cpm infused, 1,940,000 was recovered in lipids of the plasma and liver. The remainder, 1,790,000 cpm, represents radioactivity in lipids of extrahepatic tissues and that which had been removed by oxidation. The fraction of radioactivity leaving hepatic TGFA is therefore less than 2 per cent of the radioactivity in lipids of extrahepatic tissues plus the oxidized fraction, and no more than 6 per cent of the radioactivity found at 5 minutes in adipose tissue, $790,000 \mathrm{cpm}$. The proportion of radioactivity leaving hepatic TGFA increased with time, reaching 15 per cent at 45 minutes (Table IV). The results of the calculations for the other 3 dogs were similar and are shown in Table IV.

Calculations of $C^{14}: I^{131}$ ratios in lipid fractions. Table $\mathrm{V}$ shows the average $\mathrm{C}^{14}: \mathrm{I}^{131}$ ratios for infused chylomicron TGFA, plasma TGFA in the top fraction, plasma FFA, hepatic TGFA, and adipose tissue lipids.

pendent of the bulk of hepatic TGFA. These considerations make it unlikely that heterogeneity of hepatic TGFA is sufficient materially to alter our calculations.

TABLE V

Average $C^{14}: I^{131}$ ratios of lipids extracted from plasma, liver, and adipose tissue

\begin{tabular}{cccccc}
\hline \hline Dog & $\begin{array}{c}\text { TGFA of } \\
\text { infused } \\
\text { chylomicrons* }\end{array}$ & $\begin{array}{c}\text { TGFA of } \\
\text { plasma } \\
\text { chylomicrons }\end{array}$ & $\begin{array}{c}\text { Plasma } \\
\text { FFA }\end{array}$ & $\begin{array}{c}\text { Hepatic } \\
\text { TGFA }\end{array}$ \\
\hline 1 & 1.0 & 0.9 & 1.2 & 2.0 & 1.4 \\
Adipose \\
lipids
\end{tabular}

* The ratio for infused chylomicrons has been assigned the value of 1.0 ; TGFA as in Table I. 
The ratios for TGFA of the infused chylomicrons and the plasma top fraction are similar. The ratios for the hepatic TGFA are higher and indicate that de-iodination had taken place during hepatic metabolism of the chylomicrons. The ratios in lipids of adipose tissue, however, are even higher, while those for plasma FFA are considerably lower and resemble much more closely those for plasma chylomicrons.

\section{DISCUSSION}

During a constant infusion of a moderate load of chylomicrons, the TGFA of liver contained a constant proportion of about one-third of the radioactivity removed from plasma. Since chylomicron radioactivity was being infused at a constant rate, and since the proportion of the total infused radioactivtiy that had left the plasma was also constant at all times measured during the experimental period (Figure 1), it follows that the rate of uptake of TGFA radioactivity by liver and other tissues did not increase despite a progressive increase in the concentration of TGFA in plasma. This suggests that under the conditions of these experiments, a maximum rate of uptake of TGFA by the liver and other tissues was reached by 5 minutes, when the first measurements were made. The actual mass of TGFA taken up by the liver is difficult to establish precisely. Since the mean turnover rate of hepatic TGFA in the 4 dogs was $1,100 \mathrm{mg}$ per hour and since the concentration of TGFA within the liver did not rise during the infusions, it is apparent that uptake of fatty acids from all sources by the liver could not have greatly exceeded $1,100 \mathrm{mg}$ per hour. Chylomicron TGFA were infused at an average rate of $3,300 \mathrm{mg}$ per hour. Thus only about onethird of these TGFA could have been taken up by the liver. This is consistent with the finding that about one-third of the radioactivity removed from the plasma was in the liver. A portion, however, of the TGFA removed from the hepatic TGFA compartment was derived from plasma FFA (11), so that the amount of chylomicron TGFA removed by the liver must have been less than $1,100 \mathrm{mg}$ per hour. ${ }^{2}$ Moreover, if in addition

\footnotetext{
${ }^{2}$ An estimate of the quantity of hepatic TGFA derived from plasma FFA is provided in the following calculation. The mean plasma FFA concentration in the dogs was 0.5 mmole per liter and the mean plasma vol-
}

some of the radioactivity in the liver represented exchange of labeled TGFA between the plasma and liver compartments, then the net removal of chylomicron TGFA by the liver would have been still less than that calculated from the turnover rate. The rapid transfer of TGFA radioactivity between the liver and very low density lipoproteins of plasma (11) and the similarities between the metabolism of TGFA of very low density lipoproteins and chylomicrons (11) suggests that some exchange between hepatic and chylomicron TGFA did occur.

The estimate of 2 per cent at 5 minutes and 15 per cent at 45 minutes that is considered to represent the proportion of extrahepatic radioactivity derived from hepatic TGFA can only be an approximation. It is unlikely that all of the radioactivity leaving the hepatic TGFA compartment was delivered to other tissues, since a significant proportion of hepatic TGFA turnover occurs within the liver itself, by oxidation or incorporation into other lipids.

The calculation that only 6 per cent of adipose tissue radioactivity could have been derived from hepatic TGFA at 5 minutes was based on the assumption that the magnitude of uptake of TGFA was uniform throughout adipose tissue. That this was not so was demonstrated in two experiments in which the uptake of radioactivity by omental fat was found to be twice that of perirenal and subcutaneous fat.

It is apparent that the major proportion of chylomicron radioactivity enters adipose tissue and probably certain other extrahepatic tissues directly. This is consistent with the presence of lipoprotein lipase in several tissues (16), since this enzyme appears to facilitate the removal of TGFA from the blood.

The proportion of the radioactivity removed from plasma and found in adipose tissue remained constant in two dogs, but increased substantially with time in the other two. The deposition of radioactivty in adipose tissue was not influenced

ume was 0.6 liter. Assuming 1) that the fractional turnover rate of plasma FFA was 20 times per hour, 2) that one-third of plasma FFA entered the liver (11), and 3) that two-thirds of these FFA were converted to TGFA (11), then $0.5 \times 0.6 \times 20 \times 1 / 3 \times 2 / 3$, or 1.33 mmoles, or approximately $360 \mathrm{mg}$, of TGFA are derived from plasma FFA each hour. 
by the nutritional state of the animals, a finding at variance with that of Bragdon and Gordon (4). This may have been due to species difference or to inadequate preparation of our animals.

These studies have confirmed the findings of Van Handel and Zilversmit (8) that $\mathrm{I}^{131}$-labeled fatty acids are partially de-iodinated in the liver. A further finding was that an even greater degree of de-iodination occurs in adipose tissue. Therefore this part of the study provided no information about the immediate source of adipose tissue radioactivity. Since the $\mathrm{C}^{14}: \mathrm{I}^{131}$ ratios of the plasma FFA resembled those of plasma chylomicrons much more closely than those of adipose tissue, it is probable that most of the recycled FFA during this period was derived directly from the hydrolysis of plasma chylomicrons rather than from a pool in adipose tissue. On the basis of a comparison of specific activities of plasma FFA and adipose tissue FFA, Havel and Goldfien (7) concluded from a similar experiment that the labeled recycled plasma FFA were not derived from a single fatty acid pool in adipose tissue. Their results and those of the present study are consistent with the hypothesis that triglycerides are hydrolyzed by lipoprotein lipase before their constituent fatty acids enter the cells. The precise location of hydrolysis is uncertain, but experiments in animals (17) and in man (18) suggest that it is closely related to the capillary bed.

The extent of recycling of radioactivity in FFA was greater than that observed by Fredrickson, McCollester, and Ono (5) during a constant infusion of chylomicrons, but in their single experiment less fat was given.

The proportion of radioactivity removed from plasma and not found in liver and adipose tissue, "the remainder" (Figure 1), represents several pathways of TGFA metabolism. This proportion remained fairly constant during the study.

\section{SUMMARY}

During a constant 45-minute infusion of a moderate dose of chylomicrons into 4 dogs at a rate designed to simulate conditions of normal fat absorption, the triglyceride fatty acids (TGFA) of liver constantly contained about one-third of the radioactivity removed from plasma. Adipose tissue contained a fifth of the removed radioactivity, and it was assumed that oxidation and deposition into other extrahepatic tissues accounted for the remainder. The findings in two fasted dogs did not differ from those in two that had been eating normally and that received an infusion of glucose immediately before the chylomicrons.

The mean turnover rate of hepatic TGFA during the infusions was $1,100 \mathrm{mg}$ per hour. From calculations based on this turnover rate and the concentration of radioactivity in liver and other tissues, we estimated that no more than 2 per cent of the radioactivity deposited in lipids of extrahepatic tissues during the first 5 minutes could have been derived from hepatic TGFA radioactivity, and no more than 15 per cent during the subsequent 40 minutes. It is concluded that under conditions simulating the physiologic rate of influx of chylomicron lipid into the circulation, most of this lipid is removed directly by extrahepatic tissues.

\section{REFERENCES}

1. Havel, R. J., and Fredrickson, D. S. The metabolism of chylomicra. I. The removal of palmitic acid-1-C $\mathrm{C}^{14}$ labeled chylomicra from dog plasma. J. clin. Invest. 1956, 35, 1025.

2. French, J. E., and Morris, B. The removal of ${ }^{14} \mathrm{C}-$ labelled chylomicron fat from the circulation in rats. J. Physiol. (Lond.) 1957, 138, 326.

3. French, J. E., and Morris, B. The tissue distribution and oxidation of ${ }^{14} \mathrm{C}$-labelled chylomicron fat injected intravenously in rats. J. Physiol. (Lond.) 1958, 140, 262.

4. Bragdon, J. H., and Gordon, R. S., Jr. Tissue distribution of $\mathrm{C}^{14}$ after intravenous injection of labeled chylomicrons and unesterified fatty acids in the rat. J. clin. Invest. 1958, 37, 574.

5. Fredrickson, D. S., McCollester, D. L., and Ono, K. The role of unesterified fatty acid transport in chylomicron metabolism. J. clin. Invest. 1958, 37, 1333.

6. Borgström, B., and Jordan, P. Metabolism of chylomicron glyceride as studied by $\mathrm{C}^{14}$-glycerol- $\mathrm{H}^{3}$-palmitic acid labeled chylomicrons. Acta Soc. Med. upsalien. 1959, 64, 185.

7. Havel, R. J., and Goldfien, A. The role of the liver and of extrahepatic tissues in the transport and metabolism of fatty acids and triglycerides in the dog. J. Lip. Res. 1961, 2, 389.

8. Van Handel, E., and Zilversmit, D. B. Limitation of radioiodine as a label for fat. J. Lab. clin. Med. 1958, 52, 831.

9. Davis, B. D. The estimation of small amounts of fatty acids in the presence of polyoxyethylene sorbitan partial fatty acid esters ("Tween") and of serum proteins. Arch. Biochem. 1947, 15, 351. 
10. Borgström, B. Investigation on lipid separation methods. Separation of cholesterol esters, glycerides and free fatty acids. Acta physiol. scand. 1952, 25, 111.

11. Havel, R. J., Felts, J. M., and Van Duyne, C. M. Formation and fate of endogenous triglycerides in blood plasma of rabbits. J. Lip. Res. 1962, 3, 297.

12. Carlson, L. A. Determination of serum glycerides. Acta Soc. Med. upsalien. 1959, 64, 208.

13. Dole, V. P. A relation between non-esterified fatty acids in plasma and the metabolism of glucose. J. clin. Invest. 1956, 35, 150.

14. Zilversmit, D. B. The design and analysis of isotope experiments. Amer. J. Med. 1960, 29, 832.
15. Stein, Y., and Shapiro, B. Assimilation and dissimilation of fatty acids by the rat liver. Amer. J. Physiol. 1959, 196, 1238.

16. Korn, E. D. Clearing factor, a heparin-activated lipoprotein lipase. I. Isolation and characterization of the enzyme from normal rat heart. J. biol. Chem. 1955, 215, 1.

17. Robinson, D. S., and Harris, P. M. The production of lipolytic activity in the circulation of the hind limb in response to heparin. Quart. J. exp. Physiol. $1959,44,80$.

18. Fraser, J. R. E., Lovell, R. R. H., and Nestel, P. J. The production of lipolytic activity in the human forearm in response to heparin. Clin. Sci. 1961, 20,351 . 